\title{
Waste 4.0. Perceptual alterations of space and time
}

\author{
Gianluca Cuozzo, ${ }^{1, *}$ \\ ${ }^{1}$ University of Turin, Department of Philosophy and Educational Sciences, 10124 Torino, Italy
}

\begin{abstract}
Living in today's disfigured environment, where nature is but a fragment of an ancient beauty and richness, means living in a global allegory, where humans are forced to dwell in a lunar landscape - a locus of rotting trash, made up of all our discarded technological gadgets, where everything is swiftly reduced to "kipple" and "gubble" (Philip K. Dick). To put an end to this strabismus, we need to fully investigate the new 4.0 e-wastes and expose their ontological and circumstantial structure, which profoundly affects our concept of space (in terms of geopolitics) and of time (as for the durability of our sensations of wellness).
\end{abstract}

\section{The stakes: trash, unconscious, disorder, depression}

In the time of the "techno-economic unification of the planet" [1] it is easy to see the close union between consumer society, the erosion of the natural conditions for life and the exponential growth of trash - the unwanted legacy of our problematic civilisation project. Among these concepts, the less obvious, at the philosophical level, is undoubtedly that of the slag of the production process: trash. Trash can be understood both as the waste derived from gross production (an inevitable "tare" of the production of the new-net-product), and as the garbage resulting from consumer practices.

The Latin notion of purgamentum is wide enough to express both variants of the concept: waste and slag (purgamenta urbis), rubbish and leftovers (purgamenta cenae), junk (purgamenta servorum), residues and impurity (purgamen) are all part of the semantic area of the word. By metaphorical extension, however, we could also include the "waste-basket of corruption and decay" of our life-style [2], somewhere in between irrationality and systematic foulness.

We can acknowledge the distinction between production waste and consumer garbage. Slag, waste and residue are placed on the production side. Garbage and rubbish, instead, are what we do not consume (e.g., packaging) and what we get rid of after use, when it is no longer possible to make use of the properties for which the object was conceived and realised [3-7].

From an experiential standpoint, the waste/garbage concept appears obvious. All civilisations, since the dawn of history, have always come with a peculiar type of trash. Many of the archaeological sites of antiquity are nothing but deposits of rubbish: this simple observation should make us realise that the history of human civilisation is a history of residues. For example, Monte Testaccio, in Rome's homonymous neighbourhood, is also called Monte dei Cocci (Crock Hill). It is about fifty-four meters high and one kilometre in circumference, consisting mainly of testae (crocks) of pottery or amphorae destined for the fluvial trade of goods, fragments that have accumulated continually between the Augustan age and the 3rd century A.D. This is a perfect case of the hybridisation of a civilisation project, the release of trash into the environment, and the anthropisation of natural landscape.

In this example, the economic transformation of the environment has been able to absorb the side effects of the cause of alteration: the garbage promontory has turned into landscape, significantly affecting the city's topography. This case of perfect resilience is rather rare in the history of civilisation. Today we know that "waste prevention and material recovery [are] the most important objectives in waste management, followed by recycling, incineration with energy recovery and landfilling as the least preferred choice" [8].

But what's the meaning of philosophical reflection on waste, garbage and residues? Is it not entirely natural to remove and bury any trace of disorder, making it disappear from the perceptual horizon and from consciousness? So why bring to light something that should remain buried, invisible, away from our shopwindowed cities and our continuous economic growth? [9] Wouldn't this be a particular form of return of the repressed? It would indeed be the sudden eruption of the hidden, putting an end to the long period of cultural latency we call consumer civilisation, a land crossed by the new media Lethe of a social spectacularisation that has lost vernacular contact with the foundations of the Earth. This programmatic oblivion is such that it gives our "plenitudo culture" the pleonastic image a new Canaan, "where, in place of milk and honey, streams of neon flow down over ketchup and plastic" [10].

This period of latency in our civilisation becomes a powerful compulsion to repeat the waste and dilapidation of a patrimony of resources that are largely non-renewable. This has a fatal effect on the necessary

\footnotetext{
Corresponding author: gianluca.cuozzo@unito.it
} 
maintenance of the "relatively constant conditions by active control" that make life possible [11]. The compulsory principle of civilisation turns out to be a suicidal precept, which imposes itself in the injunction to consume and die: "this is the dictate of our culture. And it all ends up in trash. We make stupendous amounts of garbage, then we react to it, not only technologically, but in our hearts and the minds. We let it shape us. We let it control our thinking" [12].

It is significant that Baudrillard defined Freudian psychoanalysis a "theorisation of residues" underlying a psychic economy based on the surplus. The very notion of the uncanny (Unheimliche), could today be mainly attributed to the landscape of waste: trash brings "rats and paranoia" into the dreams of humankind; on a closer look, garbage "has a life of its own, a kind of seething vegetable menace that pushes up out of the cans and boxes, it's noisy and restless" [13].

\section{The timescale of trash}

Today's digital society is the source of a new form of trash, which is just as advanced as its sparkling and highly performing products: technological waste. Apart from some specific chemical characteristics (such as the presence of lead, chlorofluorocarbons, CFC, mercury, etc.) this waste have another important feature, which has to do with time: its rapid and continuous accumulation, at a pace that would have been inconceivable until very recently. This profoundly affects our experience, and as such is worthy of philosophical attention.

The life-cycle of many technological gadgets is very short; their duration "flashes up at the instant" [14]. On the one hand, this circumstance has to do with the hardware component of technological devices, subject to a concrete structural evolution both technical and social [10] (namely the technema: a concentration of applied science, so as to enable performances that were previously unthinkable and are always susceptible to further development). On the other hand, the duration of objects refers to what could be called their "media surface". This aspect is closely linked to simple appeal issues affecting the symbolic level; the perennial technology announcement according to which - with a cyclical and compulsive trend - "the new model has come out"; the advertisements and commercials that invite people to dispose of products suddenly marked, from one day to the next, by the stigma of obsolescence.

Usually, our devices are not antiquated in a technological sense but only in terms of image. As Anders put it, "every advertisement is an appeal to destruction" [15]. This only accelerates the rate of accumulation of waste according to emotional connotations, aesthetic factors, minimal and marginal differences established by fashion, which have nothing to do with the functionality or ergonomics of the product. This irrational-emotional factor gives our civilisation the appearance of a "gigantic 'happening', [...] through which society affords itself in the ritual destruction of materials and life the proof of its excessive affluence" [10].

Technology was once only discarded after a rather long cycle of use. The point of no return of the tool's life coincided with objective factors, which put an end to the full efficiency of the technema. The most important of these incontrovertible factors fall into two groups, intrinsic and contextual:

\section{A. Endogenous characteristics}

1. wear of essential parts that can no longer be replaced;

2. impossibility of making repairs (even ingenious) in the absence of pieces to be reintegrated into the device.

\section{B. Circumstantial characteristics}

1. effective availability of a device that allows one to perform a given job in significantly shorter times, with more precision and less effort (above all physical);

2. low cost of the new device (which must cost as much as or less than a possible ingenious repair, such as to resort to high-level craft skills = case A.1).

Only when these four conditions occur can the technema actually be said to be obsolete.

This set of circumstances profoundly affects our perception of reality. Nobody, looking at an Underwood Standard or a brand new Hermes Rocket in the 1960s, would have seen the marks of premature aging, the premonitory signs of an intrinsic crisis in the functional structure or efficiency of the product that would transform it, shortly thereafter, in a piece of junk. Unless, of course, one were Philip K. Dick. The same cannot be said of today's laptops or smartphones, which were conceived for a very different and much shorter use.

What Dick wrote in his futuristic novels, in his antiprophetic obsession with the concepts of kipple and gubble (neologisms that refer to a state of putrescent decay in which every human artefact is discarded in a very short time), is much more true for today's products - whose programmed obsolescence is a distinctive trait than for the mechanical (and rather long lasting) gadgets of his time. He was therefore able to grasp ahead of time the secret of today's industrial production, the premise of which was already present in the great US utopianconsumerist dream of the 1950s: what is lasting and sacred is not offered so much by individual products, but rather lies in the eternity and pervasiveness of the consumer cycle [16] - a cycle that seems to predetermine the very time of familiarisation with, and use of, the new gadgets ceaselessly placed on the market. In other words, in today's consumer system, money, passing from hand to hand, increases wealth value and GDP every time a discarded product is taken to the landfill [17]. The increase in material well-being is therefore a simple corollary of a destructive compulsion, 
in which the entropy of products is maximised as a function of an accelerated substitution: a sort of "némesis of decay" [18] resulting from the delirious dream of unlimited and exponential growth.

All this, in the end, means that the time of deterioration of the products is no longer due to an objective alteration dependent on endogenous factors (A.1 and A.2), but to simple contextual circumstances (B.1 and B.2), which are also distorted and subjected to the doping effect of the productive acceleration. This yields the result that industrial products bear the stigma of the prêt-à-jeter, functional for a continuous renewal on a merely psychological, symbolic and emotional basis - of our fashionable gadgets, all from the perspective of an "ostentatious consumerism" [19], that is to say, something unnecessary, to which we are drawn by our consumerist gospel (the pleasure-loving religion behind which hides the great collateral production of waste and trash).

The code name of the new technological waste, characterised by fast accumulation, difficult disposal and maximum size, is the acronym WEEE - the Waste of Electric and Electronic Equipment - or by the simple term E-Waste. The latter, paradoxically, is a receptacle of precious metals, some of which are defined as rare earth elements, including strategic ones such as lanthanum, promethium, holmium and lutetium. What's funny is that none of these minerals used in the manufacture of advanced technologies is actually recycled, and yet there is more gold in a ton of iPhones (about 8101 mobile phones) than there is in a ton of raw material from the Escondida active mines in Chile: " $0.85 \mathrm{~g}$ of pure gold compared to $275 \mathrm{~g}$ in the "melaphones", [20].

This precious waste is the dark side of our advanced scientific age, called Industry 4.0, a sort of "by-product of the creation of order" of which we only perceive the immaterial side: big data, the acceleration of satellite communications $(5 \mathrm{G})$, large digital archives, data mining, the lightness and ductility of smart devices [21]. This digital euphoria spreads to the rhythm of a globalisation that has already decided who will use the services offered by technological devices and who will watch over their wretched debris: those who enjoy it can rightfully see themselves as the bearers of virtualobjective benefits; those who have to receive the slag get instead the disused technema, in its heavy, defunctionalised materiality. Once again, the concrete substance is disguised, condemning the hardware to invisibility, to its irresponsible repression, and this is done by distributing environmental benefits and costs in well-defined areas of the planet, without the possibility of impure contamination: the world of "speeding up" (or continuous growth), and the third world/trashcan (the receptacle of waste). This process of geopolitical scotomisation brings us back to the allegorical mechanism: the material content is a mere fragment, a rune, the ruin of an (ideological) truth that is on a completely different level - this gap is as big as that between shop window and landfill, a world of advanced technology and underdeveloped countries (the whitewashed sepulcher of our modus vivendi).
In this sense, trash, to be such, implies a division of the world into two spheres - in other terms, it engenders a systemic double step inherent in today's understanding of progress: production-consumption (the solar face of our society) versus the secret place of storage-repression of the reiecta membra of gadgets now dissociated from the festive representations of the social happening (the perpetually eclipsed side of pleasure-loving consumption, in which "you shall find all that has been abandoned" [22]). That is where nature, to quote Benjamin, reveals itself in its hippocratic facies of a "petrified, primordial landscape" [23]: an agonising world, which has no future, nailed to its own mournful destiny. This also corresponds to the allegorical system of our civilisation: meaning is always found somewhere other than in the material data.

\section{Concluding remarks}

Wall-E, the Pixar robot that piles waste onto the dizzying trash skyscrapers of an uninhabited world, is the symbol of our entropic times. After removing/vertically compacting waste, Wall-E gathers curious objects in its hangar. They are all testimonies of the ancient human civilization that has now abandoned earth - a land now made inhospitable by its irremediably polluted atmosphere. These objects are allegories that still speak of hope in progress and technology, a hope now vanished in the presence of a world in ruins and submerged by waste. It is no coincidence that Wall-E looks at them with melancholy, with eyes full of regret for what used to be (or rather, for what has never been: the forever broken promise of a long-awaited happiness).

Those residual objects tell the story of failed human hopes. The robot's metallic gaze, in the face of these dismembered allegories of human aspirations, becomes suddenly human and compassionate, as if it wanted to redeem or reconstruct those fragments and historical wrecks that are the last witness of the civilisation that once was. Wall-E, ultimately, is the post-modern and technological version of Benjamin's angel of history.

Perhaps its secret dream is that "the consumer waste and the monstrous production of trash may turn into a virtuous circular economy" [19]. Perhaps it hopes in the salvific chance that "the interaction between environmental policy and technology [may be] nontrivial, and under certain circumstances can lead to desirable results" [8].

\section{References}

1. E. Morin, La Voie. Pour l'avenir de l'humanité, Fayard, Paris (2011).

2. C. Giobergia, A Path Through Landscapes of Waste, RiC., 2, 3 (2015).

3. B. Simon, M.B. Amor, R. Földényi, Life cycle impact assessment of beverage packaging systems: focus on the collection of post-consumer bottles, Journal of Cleaner Production, 112, 238-248 (2016).

4. Y. Saleh, Comparative life cycle assessment of beverages packages in Palestine, 131, 28-42 (2016). 
5. D. Visini, R. Princigallo, A. Bonoli, M. Niero, Valutazione combinata di impatti e costi ambientali: il caso delle lattine in alluminio in un'economia circolare, Ingegneria dell' Ambiente, 4(3), 240-252 (2017).

6. B. Notarnicola, G. Tassielli, P.A. Renzulli, V. Castellani, S. Sala, Environmental impacts of food consumption in Europe, Journal of Cleaner Production, 140, 753-765 (2017).

7. S. Boesen, N. Bey, M. Niero, Environmental sustainability of liquid food packaging: Is there a gap between Danish consumers' perception and learnings from life cycle assessment, Journal of Cleaner Production, 2010, 1193-1206 (2019).

8. D. Antonioli, F. Caratù, F. Niccoli, Waste Performance, Waste Technology and Policy Effects, Journal of Environmental Planning and Management, 61(11), 1-2 (2018).

9. V. Codeluppi, La vetrinizzazione del sociale. Il processo di spettacolarizzazione degli individui $e$ delle società, Bollati Boringhieri, Torino (2017).

10. J. Baudrillard, The Consumer Society, Sage, London (1998).

11. J. Lovelock, Gaia. A New Look at Life on Earth, Oxford University Press, Oxford (1979).

12. D. DeLillo, Underworld, Picador, London (2011).

13. J. Baudrillard, Quand on enlève tout, il ne rest rien, Traverses, 11: 12 (1978).

14. W. Benjamin, Illuminations, Pimlico, London (1999).

15. G. Anders, Die Antiquiertheit des Menschen. Band II: Über die Zerstörung des Lebens im Zeitalter der dritten industriellen Revolution, Beck, München (2002).

16. A. Caronia, G. Gallo, La macchina della paranoia, Book, Milano (2009).

17. Z. Bauman, Wasted Lives. Modernity and its Outcasts, Polity Press, Cambridge (2003).

18. L. Zoja, Storia dell'arroganza. Psicologia e limiti dello sviluppo, Moretti \& Vitali, Bergamo (2003).

19. S. Latouche, Bon pour la casse. Les déraisons de l'obsolescence programmée, Les liens qui libèrent, Paris (2012).

20. S. Cosimi, La nuova corsa all'oro passa dagli smartphone usati, La Repubblica, 13 April 2013.

21. M. Douglas, Purity and Danger. An Analysis of the Concepts of Pollution and Taboo, Routledge, London \& New York (2001).

22. L.B. Alberti, Le intercenali, ESI, Napoli (1998).

23. W. Benjamin, The Origin of German Tragic Drama, Verso, London (2009). 